\title{
Trypanosoma cruzi: Genetic Structure of Populations and Relevance of Genetic Variability to the Pathogenesis of Chagas Disease
}

\author{
Andréa M Macedo, Carlos R Machado, Riva P Oliveira*, Sérgio DJ Pena/+ \\ Departamento de Bioquímica e Imunologia, Universidade Federal de Minas Gerais, Caixa Postal 486, 30161-970 Belo Horizonte, \\ MG, Brasil *Joslin Diabetes Center and Department of Pathology, Harvard Medical School, Boston, MA, US \\ Chagas disease, caused by the protozoan Trypanosoma cruzi, has a variable clinical course, ranging from \\ symptomless infection to severe chronic disease with cardiovascular or gastrointestinal involvement or, occasion- \\ ally, overwhelming acute episodes. The factors influencing this clinical variability have not been elucidated, but it \\ is likely that the genetic variability of both the host and the parasite are of importance. In this work we review the \\ the genetic structure of $\mathrm{T}$. cruzi populations and analyze the importance of genetic variation of the parasite in the \\ pathogenesis of the disease under the light of the histotropic-clonal model.
}

Key words: Trypanosoma cruzi - genetic variability - mismatch repair - population structure - pathogenesis - Chagas disease

Chagas disease is a chronic illness caused by the protozoan Trypanosoma cruzi afflicting over 18 million people in the three Americas, from Southern Argentine to the Southern United States. T. cruzi is transmitted to humans by the feces of infected hematophagus triatomine bugs, blood transfusion, congenitally from infected mothers, or more infrequently by organ transplantation, contaminated food or laboratory accidents (Lambrecht 1965, Prata, 2001).

Under natural conditions the life cycle of T. cruzi alternates between an invertebrate host, one of more than 130 hemiptera from the family Reduviidae, and a vertebrate host that can be any one of more than 100 mammalian species from different orders (Lambrecht 1965, Zeledon \& Rabinovich 1981). The geographical distribution of the triatomines and the vertebrate hosts associated with the insects' preferences for specific blood sources define two transmission cycles of $T$. cruzi: a sylvatic cycle involving different species of triatomid bugs and wild animals and a domestic/peridomestic cycle in which household animals and human beings act as reservoirs.

The human disease has a very variable clinical presentation. Following the parasite infection, there is a short acute phase characterized by an abundant parasitemia, but frequently very mild and unspecific symptoms that difficult the recognition of the contagion. In less than 5\% of the cases, fatal neurological and/or cardiac complications of the acute phase can be observed. The infection then proceeds to a chronic phase, with scarce parasitemia and an unpredictable clinical course that ranges from an absence of symptoms to severe disease with cardiovascular and/or gastrointestinal involvement (Prata 2001). The

${ }^{+}$Corresponding author. Fax: +55-31-3227.3792. E-mail: spena@dcc.ufmg.br Received 17 December 2003

Accepted 7 January 2004 heart pathology is characterized by chronic myocarditis that frequently leads to cardiomegaly, congestive heart failure and arrhythmias (Tanowitz 1992). In the digestive forms of the disease, dilatation of the esophagus and/or colon (megaesophagus and megacolon, respectively) may be observed in advanced stages (Lopes et al. 1989, Adad et al. 1991). Pathologically, both the heart and digestive tract exhibit focal lymphocytic infiltrates (Brener 1992), with scarring and loss of myocardial cells in the cardiopathy (Palacius-Pru et al. 1989) and neuronal degeneration with denervation in megaesophagus and megacolon (Köeberle, 1968, Adad et al. 1991).

Geographical variations in the prevalence of clinical forms and morbidity of Chagas disease have been reported. In Brazil, the asymptomatic or indeterminate form is the most common (60-70\%), followed by the cardiac and digestive forms (20-30\% and 8-10\%, respectively); the cardio-digestive form is less frequent. However in the Central Brazil and in Chile, the digestive form of Chagas disease predominates, while it is practically non-existent in Venezuela and Central America (Luquetti et al. 1986, Dias 1992). The reason for this geographical heterogeneity and why different patients develop different clinical forms remain unexplained. It certainly cannot be explained by major genetic differences between the human populations that inhabit these areas. Thus, it is generally believed that they are primarily determined by genetic variation of T. cruzi. However, a possible role for environmental, nutritional, and immunological aspects of the host cannot be discarded.

It is interesting to observe that the relative importance attributed to parasite-related versus human-related variable has changed in the evolution of pathogenetic explanations for Chagas disease. Indeed, historically, we can discern three main phases. The first one, which we might call "parasite phase", corresponds to the period immediately following discovery of the disease, when there was no questions as to the primary pathogenetic role of $T$. cruzi. In this period there was an intense, albeit fruitless, search for biological and biochemical methods and mark- 
ers capable of establishing a link between the variability of the parasite and the clinical form of the disease. The failure of these endeavors, associated with the scarcity of parasites in the blood and tissues of chronic symptomatic patients led to the "autoimmune phase". In this second period the pathogenetic importance of the parasite was relegated to a second plane, except as providing cross-reacting epitopes capable of unleashing autoimmune reactions (Schmunis 1987, Brener 1987, Kalil \& Cunha-Neto 1996). The discovery of more sensible techniques for $T$. cruzi detection rescued the primary role of the parasite in the pathogenesis of Chagas disease. We are now experiencing the third wave, the "genomic phase", in which the illness is seen as the product of the interaction of two highly variable and coevolving genomes: the parasite genome and the human genome.

\section{THE GENOMIC PHASE}

The genomic phase of the pathogenesis of Chagas disease started in the early 90's when the presence of $T$. cruzi in chronic infected tissues was revealed by application of powerful immunohistochemical techniques developed in the past two decades (Higuchi et al. 1993). However, it was the application of the sensitive polymerase chain reaction (PCR) that provided definitive molecular evidence that clearly tied tissue lesions to the presence of the parasite (Jones et al. 1993, Brandariz et al. 1995, Vago et al. 1996a). These new studies highlighted the primary role of $T$. cruzi in the pathogenesis of Chagas disease and set the stage for establishing the notion that genomic variation of $T$. cruzi might influence the course of the disease.

\section{THE GENETIC VARIABILITY OF T. CRUZI}

Different studies including biological, biochemical and molecular ones have demonstrated that $T$. cruzi is a very heterogeneous taxon (reviewed by Macedo \& Pena 1998, Macedo et al. 2001, Devera et al. 2003). In the present review we will recapitulate some of these studies, with emphasis in those that have contributed to a better understanding of the $T$. cruzi population structure and its role for the pathogenesis of Chagas disease.

\section{ZYMODEMES}

The first experimental method that demonstrated the extent of genetic diversity of $T$. cruzi was the analysis of electrophoretic variants of cellular enzymes (isoenzymes). Based on the isozymic variability of six loci Miles et al. $(1977,1978,1980)$ proposed the existence of three isoenzymatic clusters (zymodemes Z1, Z2, and Z3) of T. cruzi. Epidemiological studies demonstrated that $Z 1$ and $Z 3$ were associated with the sylvatic cycle and Z2 with the domestic transmission cycle (Miles et al. 1978, 1980, Barret et al. 1980). Carneiro et al. (1990) identified four isoenzymatic groups (ZA, ZB, ZC, and ZD) when analyzing eight isoenzyme loci. Subsequent studies using 15 isoenzyme loci predictably evidenced much higher genetic diversity, and 43 genotypes were proposed (Tibayrenc et al. 1986, Tibayrenc \& Ayala 1988). Numerical taxonomic analysis of these data later suggested the existence of two major highly heterogeneous phylogenetic lineages of $T$. cruzi that differed in several biological properties (Tibayrenc
1995). More recently, Brisse et al. (2000) identified five lower phylogenetic subdivisions within one of the lineages and proposed the existence of six principal discrete T. cruzi groups (so-called lineages I, IIa, IIb, IIc, IId, IIe).

\section{SCHIZODEMES}

The first studies of DNA polymorphism in T. cruzi were published in 1980 by Morel et al. who reported on restriction fragment length polymorphism (RFLP) typing of kDNA minicircles. Parasite populations displaying identical or very similar kDNA minicircle restriction patterns were called schizodemes. kDNA RFLP analyses unraveled an unexpected amount of genetic diversity in T. cruzi, although some correlation was seen with the isozyme classification, demonstrating that linkage disequilibrium extended even between different (nuclear and mitochondrial) genome compartments (Tibayrenc \& Ayala 1987). Together with cloning experiments, kDNA restriction analysis demonstrated for the first time that single strains of T. cruzi could contain two or more distinct clones (Morel et al. 1980). The existence of these multiclonal T. cruzi strains was confirmed later by several groups using different techniques (Deane et al. 1984, Marques-Araújo \& Chiari, 1988, Carneiro et al.1990, Macedo et al.1992, Oliveira et al. 1998, 1999).

\section{LOW STRINGENCY SINGLE SPECIFIC PRIMER (LSSP)-PCR}

An alternative and more sensitive way to study the polymorphism of the kDNA is the LSSP-PCR method (Vago et al. 1996a). In this technique a previously purified DNA amplicon is subjected to PCR using a single specific primer under very low stringency conditions. The primer hybridizes specifically to its complementary region and also nonspecifically to multiple sites within the fragment, in a sequence-dependent manner, thus producing a highly complex set of reaction products that can be resolved by electrophoresis to generate 'gene signatures' (Pena et al. 1994, Pena \& Simpson, 1996). LSSP-PCR has been successfully applied to the $\sim 330 \mathrm{bp}$ variable DNA fragment of $T$. cruzi $\mathrm{kDNA}$ minicircles to produce the ' $\mathrm{kDNA}$ signatures', allowing for the first time to profile parasites present in the tissues of chronically infected patients (Vago et al. 1996b). The initial idea of the differential tissue tropism playing fundamental importance in determining the pathogenesis of Chagas disease, proposed as early as 1911 (Vianna 1911) was revitalized when it was shown that parasites presenting different genetic profiles could be found in distinct tissues (esophagus and heart) of the same patient (Vago et al. 2000). Moreover, in a study of doubly infected mice, we found a strong correlation between the strain profile (JG or Col1.7G2) and the type of lesion in the heart and rectal tissues (Andrade et al. 1999).

\section{RANDOM AMPLIFIED POLYMORPHIC DNA (RAPD) ANALYSIS}

The PCR-based RAPD technique and the less used but closely related simple sequence repeat anchored primer PCR (SSR-PCR) have provided a sensitive approach for $T$. cruzi profiling and constitute useful tools for establishing genetic relationship among isolates (Dias Neto et al. 1993, Steindel et al. 1993, Tibayrenc et al. 1993, Oliveira et al. 1997, Brisse et al. 2000). Complex and strain-specific 
banding patterns were evidenced for different $T$. cruzi populations, although no correlation with clinical aspects has been found (Oliveira 1997). However, when we compare the RAPD profiles of strains isolated from patients in the chronic phase of the disease, with isolates from patients in the acute phase, and with $T$. cruzi populations obtained from sylvatic vectors and mammals, a clear increasing gradient in variability is observed (Table I). These results are compatible with the idea that not all $T$. cruzi strains are capable of establishing effective infections in Homo sapiens and that humans thus function as a filter in selecting more adapted sub-populations (Macedo \& Pena 1998). Even in the domestic environment, the probability of acquiring Chagas disease from one bite of an infected bug has been estimated to be only about one in a thousand (Prata 2001).

RAPD patterns have being used in numerical taxonomy studies. A strong correlation has been observed between RAPD profiles and zymodemes (Steindel et al. 1993, Tibayrenc et al. 1993). Moreover, RAPD profiling was also utilized for corroborating the T. cruzi taxon division in two major lineages (Tibayrenc 1995, Souto et al. 1996).

\section{MINI EXON POLYMORPHISM}

The mRNA of trypanosomes is unique in that most, if not all, mature species bear an identical 35-bp splicer leader (SL) at their 5'-termini (Borst \& Greaves 1986). This SL is encoded in blocks of tandemly repeated units, the miniexon genes (ME). Comparative alignment of ME from different $T$. cruzi strains showed the presence of highly conserved sequences regions of 39 bp (the exons), similar regions of $73 \mathrm{bp}$ with more than $98 \%$ of identity (corresponding to the introns) and divergent intergenic regions (less than 59\% of similarity) (Murthy et al. 1992, Souto et al. 1996) (Fig. 1). By using a multilocal PCR strategy it was possible to cluster $T$. cruzi strains into two groups according to the amplification products. Strains that yielded 300 bp products were designated as belonging to group 1 and those that yielded 350 bp products were designated as belonging to group 2 (Souto et al. 1996). Subsequent analysis of mini-exon gene sequences of $\mathrm{Z} 3$ strains recognized a sub-clade inside of group 2 characterized by a $\sim 50 \mathrm{bp}$ insertion/deletion in the non-transcribed spacer region of the mini-exon (Fernandes et al. 1998). New sets of primers were designed to amplify the Z3 strains (Fernandes et al. 2001).

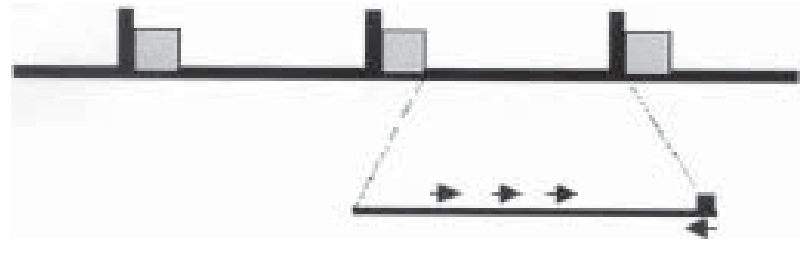

Fig. 1: schematic representation of the Trypanosoma cruzi miniexon (ME) locus. The ME locus is organized as tandem repeated units in which the exon region are conserved throughout the kinetoplastida (black boxes). Intron regions are indicated by the grey boxes and the non-transcribed spacer is represented by the black connecting line. ME typing is based on a multiplex polymerase chain reaction using an exon-specific primer (right arrow) and lineage-specific primers located in the spacer region.

\section{RDNA POLYMORPHISMS}

In trypanosomes, the ribosomal cistron exhibits a singular organization. Both the small subunit (SSU) and the large subunit (LSU) are considerably larger than the typical eukaryotic rRNA species. Particularly interesting is the LSU that contains two-high-molecular weight RNAs $(24 \mathrm{~S} \alpha / 24 \mathrm{~S} \beta)$ and six low-molecular-weight RNA $\left(\mathrm{S}_{1}-\mathrm{S}_{6}\right)$ components (Leon et al. 1978, Hernandez et al. 1990, Arruda et al. 1990). The rDNA cistron is constituted of repeated sequences in which the coding regions of the SSU and the LSU are separated by two internal transcribed spacers. The ITS 1 separates the coding region of the $18 \mathrm{~S}$ subunit and the 5.8 S rDNA, and the ITS2 separates $5.8 \mathrm{~S}$ rDNA sequence from the 24S rDNA (Fig. 2). Comparison between the 24S $\alpha$ rRNA gene of $T$. cruzi and other trypanosomatids showed high homology except for discrete regions. The most divergent domain (D7) is a segment of about $100 \mathrm{bp}$ located at the 3' end of T. cruzi gene (Arruda et al. 1990, Souto \& Zingales 1993). Initially, PCR amplification of a sequence from the D7 domain revealed a dimorphism when DNA from different $T$. cruzi strains was used (Souto \& Zingales 1993). Three different groups or lineages of $T$. cruzi strains could be detected. Strains from lineage 1 gave a 125 bp product and another group of strains (lineage 2) gave a 110 bp product. A third group presenting both PCR products and denoted group $1 / 2$ was later detected (Souto et al. 1996).

TABLE I

Analysis of genetic variability of 58 Trypanosoma cruzi strains by randon amplified polymorphic DNA according to their origin

\begin{tabular}{lcccc}
\hline Sample & $\begin{array}{c}\text { Number } \\
\text { of } \\
\text { strains }\end{array}$ & $\begin{array}{c}\text { Average } \\
\text { number of } \\
\text { bands per track }\end{array}$ & $\begin{array}{c}\text { Average number } \\
\text { of shared bands in } \\
\text { different strains ( } \pm \text { s.d.) }\end{array}$ & $\begin{array}{c}\text { Average } \\
\text { proportion of } \\
\text { shared bands }\end{array}$ \\
\hline $\begin{array}{l}\text { Strains isolated from non-human sources } \\
\text { Strains isolated from patients with acute Chagas disease }\end{array}$ & 11 & $45.7 \pm 7.8$ & $10.2 \pm 8.9$ & $22 \%$ \\
$\begin{array}{l}\text { Strains isolated from patients with asymptomatic chronic } \\
\text { Chagas disease }\end{array}$ & 14 & $55.0 \pm 10.3$ & $21.5 \pm 13.9$ & $39 \%$ \\
$\begin{array}{l}\text { Strains isolated from patients with symptomatic chronic } \\
\text { Chagas disease }\end{array}$ & 22 & $56.9 \pm 6.7$ & $28.1 \pm 16.8$ & $51 \%$ \\
\hline
\end{tabular}




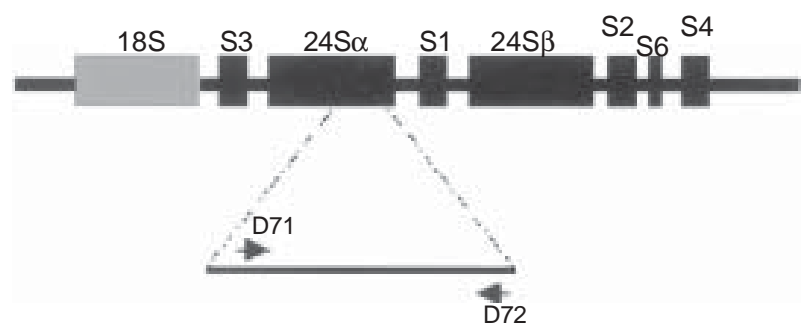

Fig. 2: schematic organization of Trypanosoma cruzi rDNA cistron. The small subunit (SSU) is indicated by a grey box and the large subunit (LSU) by black boxes. The rDNA cistron is constituted of repeated sequences in which the coding regions of the SSU and the LSU are separated by two internal transcribed spacers (ITS). The ITS 1 separates the coding region of the $18 \mathrm{~S}$ subunit and the 5.8 S rDNA, and the ITS2 separates 5.8 S rDNA sequences from the 24S rDNA. rDNA typing is performed using primers D71 and D72 that amplifies a dimorphic region at the 3' end of the $24 \mathrm{~S} \alpha \mathrm{rRNA}$ gene

The phylogenetic relationship of strains from the rDNA group 1,2, and 1/2 is still under intense investigation. Studies on RAPD and mini-exon profiling had shown that the strains of the D7 rDNA group 1/2 were more genetically related to the rDNA lineage 1 than rDNA lineage 2 (Souto et al. 1996). However Zingales et al. (1999) sequenced both alleles of the D7 rDNA from a strain of group $1 / 2$ and while the alignment of the sequence type 1 placed this strain among lineage 1 strains, the sequence type 2 did not allow the clear position of the strain in the tree. In fact, depending on the algorithm used group $1 / 2$ in some tree seemed to be more related to lineage 1 and in the other trees to lineage 2 .

Additionally, when comparing 18S and D7-24S $\alpha$ rDNA sequences, Kawashita et al. (2001) found that T. cruzi could be organized into four riboclades. The riboclade 1 (rDNA group 1) could be separated from the others, but the riboclade 2 (containing the strains rDNA group 2) proved to be a sister group of the two additional riboclades 3 and 4 , which grouped representative strains from zymodeme $\mathrm{Z3}$ and rDNA group 1/2.

More recently, extra D7 PCR products of 117/119 bp (Pimenta 2002) or 120/130 pb (Brisse et al. 2001) were found. Brisse et al. (2001) combine data from 18S, D7 region of 24Sa rDNA and mini-exon data to reinforce the their hypothesis of a subdivision of the T. cruzi into six lineages (I, IIa, IIb, IIc, IId, IIe).

\section{KARYOTYPING}

The chromatin of $T$. cruzi is poorly condensed during mitosis and distinct chromosomes cannot be visualized by microscopic methods. The development of the pulsedfield gel electrophoresis (PFGE) technique made possible the identification of 20 chromosomal bands ranging from $450 \mathrm{~Kb}$ to $3500 \mathrm{~Kb}$ for CL Brener, the model clone of the $T$. cruzi genome initiative (Santos et al. 1997, Porcile et al. 2003). However, the intensities of different chromosomal bands vary in ethidium bromide stained gels, indicating that the chromosome number may be possibly much higher than 20 (Santos et al. 1997).

Annealing studies with several DNA probes show hybridization signals in pairs, presumably in homologous chromosomes, which in many cases differ in size. In fact extensive chromosomal size polymorphism has been revealed among different strains and even between clones of the same strain of T. cruzi (Henriksson et al. 1995, Alves et al.1996). This polymorphism can be seen in most trypanosomatids and has been attributed to expansion/ contraction of tandem repeats (Dujardin et al. 1995). Moreover, differences in ploidy for one or more chromosomes (aneuploidy) have been also observed (reviewed by Herinksson et al. 1996).

Attempts have been made to reconstruct the evolutionary history of $T$. cruzi by using the absolute chromosomal size difference index (aCSDI) as a genetic distance among the isolates. This method assumes that the genomic distance between two organisms is the sum of the size differences between their homologous. The phenetic trees obtained had defined initially two (Henriksson et al. 2002) and later three (Pedroso et al. 2003) major clusters in T. cruzi encompassing respectively the strains from D7 rDNA group 1, 2 and 1/2.

\section{MICROSATELLITE ANALYSES}

The disclosure of the $T$. cruzi microsatellites (polymorphic tandem repeats of 2-6 bases long simple motifs) has provided a new tool for the analysis of the population structure of the parasite (Oliveira et al. 1998). These DNA markers are extremely polymorphic and are dispersed throughout the parasite's nuclear genome. The microsatellite analysis of different T. cruzi strains and clones constituted a simple screening test to estimate if a $T$. cruzi strain is a monoclonal or a multiclonal population (Oliveira et al. 1998, 1999, Macedo et al. 2001). By using microsatellite analyses it was demonstrated that the percentage of multiclonal (or aneuplody) populations decrease progressively as we compare strains isolated from the sylvatic cycle with those isolated from man, confirming the previous idea of a human filter selecting more adapted strains (Table II- Oliveira et al. 1998, 1999, Macedo et al. 2001).

The T. cruzi microsatellite profile also has been used for phylogenetic investigations. In initial studies involving 53 T. cruzi populations isolated from different geographical areas, the tree topology indicated clustering of the strains in three major branches. The first two of these branches contained respectively the strains belonging to D7 rDNA group 1/mini-exon group 1 and those of D7 rDNA group 2/mini-exon group 2 . The third branch was less homogeneous and enclosed strains from the D7 rDNA

\section{TABLE II}

Proportion of Trypanosoma cruzi strains with more than two microsatellite peaks according to their origin

\begin{tabular}{lcc}
\hline Sample & $\begin{array}{c}\text { Total } \\
\text { number }\end{array}$ & $\begin{array}{c}\text { Strains with more } \\
\text { than two peaks }\end{array}$ \\
\hline $\begin{array}{l}\text { Strains isolated from } \\
\text { non-human sources }\end{array}$ & 40 & $23(58 \%)$ \\
$\begin{array}{l}\text { Strains isolated from patients } \\
\text { with chronic Chagas disease }\end{array}$ & 79 & $8(10 \%)$ \\
\hline Total & 119 & $21(18 \%)$ \\
\hline
\end{tabular}


group 1/2 together with some strains presenting D7 rDNA type 2, but mini-exon type 1(Oliveira et al. 1999, Macedo et al. 2001). It was proposed that strains presenting D7 rDNA type 2 could be split into two distant subgroups with different origins, and that one of these subgroups could be more related to the strains from group 1/2 (Souto et al. 1996, Oliveira et al. 1998, Macedo et al. 2001). Further work using microsatellite analysis demonstrated that the third cluster may correspond to hybrid T. cruzi strains (Augusto-Pinto et al. manuscript in preparation).

\section{OTHER GENE POLYMORPHISMS}

Using two different nuclear genes (trypanothione reductase - TR and dihydrofolate reductase-thymidylate synthase - DHFR-TS) and a region of the mitochondrial DNA partially encompassing the maxicircle-encoded genes (cytochrome oxidase subunit II - COII and NADH dehydrogenase subunit 1 - ND1) Machado and Ayala (2001) proposed the division of T. cruzi strains into four different clades, named A, B, C, and D. Clade A included all DNA sequences from strains belonging zymodeme 1 (Z1). However, the DNA sequences obtained from strains of $\mathrm{Z} 2$ and $\mathrm{Z} 3$ were not monophyletic and were clustered into two (mitochondrial data) or three (nuclear data) distinct clades (B, C, and D).

Augusto-Pinto et al. (2003) cloned and sequenced the mismatch repair mutS homologue 2 (MSH2) of $T$. cruzi, which proved to be polymorphic. Examination of 13 different strains identified three clusters of sequences that could be used for dividing the taxon into three distinct clades (A, B, and C). It was shown that strains belonging to clade A correspond to those presenting D7 rDNA 2, mini-exon 2, and zymodene Z1 (that were initially named as group 2 by Souto et al. 1996, but latter renamed T. cruzi I, see about). Similarly strains belonging to clade C correspond to those strains sharing D7 rDNA 1, mini-exon 1, zymodeme $\mathrm{Z} 2$ and initially refereed as group 1 by Souto et al. (1996) and latter T. cruzi II. Into the third clade B were grouped the hybrid strains such as those presenting D7 rDNA $1 / 2$ or zymodeme Z3.

\section{THE MAJOR LINEAGES IN T. CRUZI}

As pointed out previously, T. cruzi is a very polymorphic species and the overall population structure is far from being completely understood. Until the end of 80's, the prevalent idea was that $T$. cruzi strains could not be grouped into few discrete groups that might represent natural taxa (Morel et al. 1980, Tibayrenc et al. 1986). Instead, a multiclonal population structure was proposed, with the different clones evolving from a very ancient ancestral, basically by clonal reproduction (Tibayrenc et al. 1986, Zhang et al. 1988). However the identification of a strong correlation between different DNA markers such as mini-exon, D7-24S rDNA, RAPD and microsatellites generated a consensus about the existence of two major phylogenetic lineages within the taxon (Tibayrenc 1995, Souto et al. 1996, Nunes et al. 1997, Zingales et al. 1998). The basic dichotomy of the species was further correlated with a plethora of epidemiological, biochemical, biological and molecular markers (Fernandes et al. 1998, Oliveira et al. 1998, Macedo et al. 2001, Henriksson et al.
2002, reviewed by Momen 1999, Zingales et al. 1999, and Buscaglia \& Di Noia 2003), but the nomenclature of the major groups became very confusing. In 1999, in an effort to homogenize the nomenclature, the two major lineages were renamed T. cruzi I and T. cruzi II (Satellite Meeting 1999, Table III). At the time, putative hybrid strains such as those belonging to D7- rDNA group 1/2 (Souto et al. 1996), clonet 39 (Tibayrenc 1995) and Z3 could not be unequivocal classified as $T$. cruzi I or T. cruzi II. Thus it was established that these strains should remain identified as $T$. cruzi without any other specification, until new insights could clarify the phylogenetic relationship of the group (Satellite Meeting 1999).

\section{IS T. CRUZI A SINGLE SPECIES?}

One important question that arises is the significance of the division of T. cruzi into discrete major lines. Should be $T$. cruzi I and T. cruzi II considerate as separated subspecies or even different species?

The modern concept of a species is that of a population that is simultaneously a reproductive community, an ecological unit and a genetic unit. Obviously, basically clonal asexual species such as T. cruzi cannot be defined in reproductive terms and thus the concept of genetic unity, in the sense of a shared genome, becomes critical. The question here is how much intraspecific genomic variability can be allowed before we start splitting the species into different ones. In attending this question Briones et al. (1999) analyzed the rDNA cistron and found that $T$. cruzi I and II constitute monophyletic groups with a genetic distance compatible with a coalescence time of 88 million years before present. This genetic distance is comparable to that separating different Leishmania species. They proposed also that $T$. cruzi emerged as a species over 150 million years ago and that the major groups remained separated from each other during the insulation of South America (from 100 to 38 MYR ago), thus favoring their cryptic speciation. According to this view, $T$. cruzi I was autochthonous to South America and coevolved with marsupials and edentates, whereas T. cruzi II co-evolved in North American placental mammals (Briones et al. 1999).

One might alternatively try to define a single species based on the fact that $T$. cruzi clones have similar life cycles and cause Chagas disease. However even this latter criterion falls apart when we consider the clinical pleotropism of the disease. The evolutionary diversification of $T$. cruzi pre-dated the appearance of $H$. sapiens by several tens of millions of years. Indeed, the first contact of $T$. cruzi with humans seems to have occurred when immigrants from Central Siberia peopled the Americas, less than 15,000 years ago, in the late Pleistocene (Santos et al. 1999). Thus, specific adaptation to human hosts, to whatever extent it exists, must have evolved independently in separate lineages, and may not have evolved at all in some T. cruzi (Macedo \& Pena 1998). Several findings strengthen this point of view. T. cruzi I strains are preferentially encountered in the sylvatic cycle of transmission of Chagas disease while T. cruzi II strains are strongly associated with the domestic cycle, at least in Brazil (Fernandes et al. 1998, 1999, Zingales et al. 1998). T. cruzi 
II is apparently more associated with primates and particularly with human infections while $T$. cruzi I, which seems to be more adapted to marsupials, is only occasionally isolated from humans and even then in regions where T. cruzi is enzootic. Until now all parasites isolated from soropositive individuals from endemic regions in Brazil belong to T. cruzi II major lineage. (Fernandes et al. 1998, 1999, Zingales et al. 1998, reviewed by Zingales et al. 1999). Recent unpublished results obtained in our laboratory have shown that all parasites typed directly from affected heart and/or esophagus tissues of Brazilian patients with clinical forms of the disease are from the $T$. cruzi II lineage (J Freitas, AM Macedo, manuscript in preparation).

\section{THE ORIGIN OF THE NATURAL HYBRID STRAINS}

The occurrence of genetic exchange with homologous recombination has just recently been demonstrated for $T$. cruzi (Stothard et al. 1999, Gaunt et al. 2003). However, in the last two decades evidence for some kind of genetic exchange in T. cruzi was brought to light (reviewed by Tait 1980, Gibson \& Stevens 1999). Most of the evidence was based on the identification of putative natural hybrid strains by isoenzyme analyses (Bogliolo et al. 1996, Higo et al. 2000), RAPD (Carrasco et al. 1996), karyotyping and/ or gene sequencing (Sturn et al. 2003).

What is the origin of the natural hybrid populations detected in $T$. cruzi ? An interesting observation is that most of them, if not all, (see below) correspond to those strains that could not be appropriately classified into $T$. cruzi I or T. cruzi II major lines (satellite Meeting 1999, Momen 1999). The list of such unclassifieable T. cruzi populations includes strains presenting both alleles for the locus D7 24S $\alpha$ rDNA (group 1/2 - Souto et al. 1996), strains from clonet 39 (Tibayrenc 1995, Tibayrenc \& Ayala 1998), strains belonging to zymodeme Z3 (Fernandes et al. 1998, 1999) and strains showing discrepant alleles for different loci, for example, D7 type 2 miniexon type 1 (Souto et al. 1996). There were no putative hybrids among the strains clearly classified as $T$. cruzi I or T. cruzi II, except for CL Brener. Another possibly hybrid is the Tulauhén strain. Here, the complication is that there is more than one strain circulating among different laboratories with the same name; some of them are genuinely T. cruzi I, but others are T. cruzi II or hybrids (Souto et al. 1996, Brisse et al. 2001, Augusto-Pinto et al. 2003). CL Brener, the clone chosen for the $T$. cruzi genome project, was initially classified as T. cruzi II, on the bases of D7 and mini-exon gene typing (Souto et al. 1996). However, several lines of evidence have demonstrated that CL Brener is in fact a hybrid strain presenting characteristics from both major lines and being genetically much more closer to those strains belonging to D7 rDNA group 1/2 than to T. cruzi II (Brisse et al. 2001, Pedroso et al. 2003, Augusto et al. 2003).

More recently there was an effort to classify the hybrid strains into the $T$. cruzi I or T. cruzi II major lineages. However this turned out to be a more difficult task than initially expected, since depending on the polymorphic marker used, the hybrid strains seemed to be closer related to one or other major lineage. As an example we can cite the strains belonging to the D7 group $1 / 2$ (Souto et al.
1996). As mentioned before, studies on RAPD and miniexon profiling showed that these strains seemed to be genetically closer to T. cruzi II than T. cruzi I. However, sequence analyses of the alleles of D7 or 18S rDNAs put the $1 / 2$ strains together with $T$. cruzi I or T. cruzi II depending on the algorithm used (Zingales et al.1999, Kawashita et al. 2001). In order to better accommodate the hybrid strains within T. cruzi II, Brisse et al. (2000, 2001) proposed a subdivision of this major lineage into five lower subgroups (named IIa, IIb, IIc, IId, and IIe). However this strategy did not take into account the fact that depending on the characteristic analyzed the hybrids seem to be more related to the $T$. cruzi I or even very different from both major lines (Souto et al. 1996, Zingales et al. 1999, Machado $\&$ Ayala 2001, 2002, Augusto-Pinto et al. 2003). An alternative viewpoint now emerging is that the hybrid strains could constitute a third major lineage on $T$. cruzi taxon, maybe the T. cruzi III lineage (Machado \& Ayala 2001, 2002, Augusto-Pinto et al. manuscript in preparation).

Gaunt et al. (2003) have shown evidence that the hybridization of $T$. cruzi strains occurs only with nuclear genome without mitochondrial fusion, so if the natural hybrid strains have the same evolutionary lineage the hybrids will also have the same type of mitochondrial DNA. Machado and Ayala $(2001,2002)$ demonstrated that the mitochondrial clade $\mathrm{B}$ is constituted by at least two Z3 strains and other hybrid strains from isoenzyme type 39 and 43. Recently, Augusto-Pinto et al. (manuscript in preparation) showed that all strains presenting hybrid molecular markers in their nuclear genomes have a specific mitochondrial genome distinct from both the T. cruzi I and $T$. cruzi II major lineages. These results suggest that the hybrid $T$. cruzi strains might represent a truly diverging phylogenetic lineage of $T$. cruzi, conceivably originating from an ancient recombination event between $T$. cruzi I and T. cruzi II strains, rather than from multiple recent hybridization episodes.

\section{CLONAL POPULATION STRUCTURE VERSUS SEXUAL REPRODUCTION IN T. CRUZI}

Analyses of several genetic loci among different parasite populations have demonstrated that T. cruzi populations present drastic departures from Hardy-Weinberg expectations and strong linkage disequilibrium (reviewed in Ayala 1993). These findings have been interpreted as suggestive that $T$. cruzi has a clonal population structure in which sexual reproduction is rare or absent. In this perspective each clone represents an independent lineage that divides by binary division and evolves by mutation only from an ancient ancestral (Tibayrenc et al. 1986, Zhang et a. 1988).

One expectation of this would be that $T$. cruzi, as an asexual organism, should present the "Meselson effect", i.e., in the absence of sexual recombination, the two alleles at any given locus evolve independently from the moment of setting up the asexual lineage and nothing prevents then from diverging. Indeed, a great allele divergence has been found in the asexual Bdelloid rotifers (Welch and Meselson 2000). Analyzing the DNA sequence of four different genes from Bdelloid, Welch \& Meselson (2000) showed that the genes presented allele divergence 
as great as $54 \%$ in degenerate sites (third positions in codons, where any of the four bases can be found in the DNA without changing the amino acid in the correspondent protein). In T. cruzi however, microsatellite data show an excess of homozygosity (Oliveira et al. 1998). Indeed, a recent study on gene sequencing did not detect any significant divergence of the two alleles in strains belonging to $T$. cruzi I or T. cruzi II lineages (Machado \& Ayala 2001). Contrasting with the asexual rotifers, allele divergence in $T$. cruzi was only observed in nuclear genes of some strains presenting hybrid isoenzyme specimens and was better attributed to hybridization events rather than a signal of ancient asexuality. Therefore it has been proposed that one or more of four different possible mechanisms, automixing, sexuality (gene exchange), gene conversion and mitotic recombination, could be involved in decreasing the T. cruzi allele divergence (Machado \& Ayala 2001).

Until now there is no evidence for automixing in $T$. cruzi. Conversely, Gaunt et al. (2003), have demonstrated that genetic exchange can occur in the parasite. Working with two strains of $T$. cruzi I carrying different drug-resistance markers, they were able to recover six double-drugresistant progeny clones from the mammalian stage of the life cycle. The hybrids showed a fusion of parental genotypes with loss of alleles and homologous recombination. Isoenzyme and karyotype analyses have confirmed that the putative hybrid clones really shared characters from both parental populations.

As point out above, there are many evidences for natural occurrence of hybrid strains in $T$. cruzi, but in relation to the "Meselson effect", the hybrid strains do not explain the high homozygosity observed in T. cruzi. Instead initially the presence of hybrids would be expected to increase the divergence between the alleles in the same locus. Of course, a meaningful question is which is the frequency of the "recombination events" between strains from the $T$. cruzi I and T. cruzi II lineages, since excess homozygosity could result from either clonality or from aneuploidy with subsequent allele loss (i.e. from hemizygosity, which is experimentally indistinguishable from homozygosity). We cannot rule out the possibility that cell fusion followed by allele loss may be a common feature in these strains. In this case T. cruzi would not have a typical asexual reproduction and the absence of the "Meselson effect" could be explained. However, this possibility seems a priori unlikely, and other mechanisms should be entertained.

Homogenizing mechanisms like mitotic recombination or genetic conversion could limit the "Meselson effect", decreasing the genetic diversity within and between individuals. Schon and Martens (2003) showed that the ancient asexual ostracod species Darwinula stevensoni shows very low nucleotide divergence in three nuclear regions. Likelihood permutation tests confirmed the presence of gene conversion in the multi-copy internal transcribed spacer sequence, but rejected rare or cryptic forms of sex as a general explanation for the low genetic diversity in the organism (Schon \& Martens 2003).

The human Y chromosome is another example of genetic conversion as homogenizing mechanism (Skaletsky et al. 2003). It presents a male-specific region (MSY), which is a mosaic of heterochromatic sequences and three classes of euchromatic sequences: X-transposed, X-degenerate and ampliconic. There are evidences that the X-degenerate and ampliconic sequences were transmitted exclusively

TABLE III

Biological and molecular markers used for characterization of Trypanosoma cruzi sub-division ${ }^{a}$

\begin{tabular}{llll}
\hline T. cruzi I & T cruzi II & Hybrid & Reference \\
\hline Type III & Type II & Type I & Andrade (1974) \\
Strain-group 1 & Strains-group 2 & & Miles et al. (1977) \\
Type 1 & Type 2 & & Miles et al. (1978) \\
& Romanha et al.(1979) \\
Zymodeme 1 & Zymodeme 2 & Zymodeme B & Barret et al. (1980) \\
Group 1 & Group 2 & Zymodeme 3 & Schottelius (1982) \\
Type 2 (PNA) & Type 1 (WGA) & & Tibayrenc \& Miles (1983) \\
Braz ZI & Braz Z2 & Bol Z2 & Zillman \& Ebert (1983) \\
Group A & GroupB & & Miles et al. (1984) \\
Chilean Z1 & Chilean Z2a & Chilean Z2b & Tibayrenc et al. (1984) \\
Isoenzyme strain (IS) 1 & IS 2e & IS 2 & Tibayrenc \& Ayala (1988) \\
Zymodeme 17 & Zymodeme 30 & Zymodeme 39 & Muhlpfordt \& Berger (1990) \\
DNA group 1 & DNA group 2 & & Clark \& Pung (1994) \\
Ribodeme II & Ribodeme I & Tibayrenc (1995) \\
Group I & Group II & Genotype 39 & Souto et al. (1996) \\
Lineage II & Lineage I & Group 1/2 & Andrade \& Magalhães (1997) \\
Biodeme III & Biodeme II & Biodeme I & Nunes et al. (1997) \\
Group II & Group I & & Tibayrenc (1998) \\
1st Major Clade & 2nd Major Clade & Lower Clade & Machado \& Ayala (2001) \\
Clade A & Clade C & Clade B & Augusto-Pinto et al. (2003) \\
Clade A & Clade C & Clade B &
\end{tabular}

$a$ : modified from Momen (1999) 
through the male germline, and neither participated in meiotic crossing over with a homologous counterpart. In the $\mathrm{Y}$ chromosome the shutting down of X-Y crossing over during evolution triggered a monotonic decline in gene function. This model is corroborated by the presence, in the MSY's X-degenerate sequences, of decayed, intron-bearing pseudogenes. However, in the ampliconic regions, which present functional genes, there is an abundant Y-Y gene conversion as a homogenizing mechanism that permitted this region to overcome the problem of sexual absence. This process might provide a mechanism for conserving gene functions across evolutionary time in the absence of crossing over (Skaletsky et al. 2003).

It remains to be established if genetic conversion and/ or mitotic recombination are important phenomena for homogenization of gene sequences in T. cruzi. In this aspect, it was shown that $T$. cruzi cells present atypical high resistance to ionizing radiation (IR), which could be associated with recombination-based DNA repair (Takeda et al. 1986, Amato-Neto et al. 1996).

\section{MECHANISM OF T. CRUZI GENETIC VARIATION?}

Another intriguing characteristic of $T$. cruzi is how it achieves remarkable heterogeneity among the strains and even clones, paradoxically maintaining at same time high levels of individual homozigosity. One possibility that is unlikely, but cannot be discarded, is that the homozigosity is artefactual and in reality represents hemizigosity occurring in aneuploid clones. Ignoring this possibility for the moment, and working within the paradigm of a clonal structure for the T. cruzi populations, one could then expect that mutation and DNA repair would play a role.

The function of mismatch repair (MMR) in decreasing the mutation rate is well understood (reviewed by Hsieh 2001). It is clear that the loss of this mechanism plays a determinant role in some types of human cancers (Peltomaki 2003). However, pathogenic microorganisms presenting defective MMR have been isolated in a proportion much higher than initially expected and it has been argued that an increased mutation rate could permit greater host adaptability for these organisms (LeClerc et al. 1996).

As already discussed above, the sequence of the $T$. cruzi MSH2 homologue gene identified tree haplogroups: A (T. cruzi I), B (hybrid strains) and C (T. cruzi II) (Augusto-Pinto et al. 2003). The MMR efficiency was further investigated among strains belonging to each haplogroup by analyzing two phenotypes: microsatellite instability (in the presence of hydrogen peroxide) and cisplatin resistance. Microsatellite instability was observed only for strains belonging to haplogroups B and $\mathrm{C}$, but not in haplogroup A. Furthermore cells from haplogroups $\mathrm{B}$ and $\mathrm{C}$ were considerably more resistant to cisplatin treatment, a characteristic known to be conferred by deficiency of mismatch repair in eukaryotic cells (Fujieda et al. 1998). Altogether, these data suggest that strains belonging to haplogroups B and C may have decreased mismatch repair ability at stress conditions and consequently higher mutations rates when compared with those belonging to haplogroup A (Augusto-Pinto et al. 2003). Up to now the mutation rates for each of the T. cruzi major lineages are unknown, but it is noteworthy that haplogroups B and C, which apparently have decreased mismatch repair efficiency, are involved in most cases of human infection (Buscaglia \& Di Noia 2003).

\section{CLINICAL IMPLICATIONS OF T. CRUZI GENETIC VA-} RIABILITY

Humans could be considered a recent accident in the evolutionary history of $T$. cruzi. It is estimated that $T$. cruzi emerged as a species over 150 million years ago and the first contact with man is supposed to be much more recent, in the late Pleistocene, approximately 15,000 years ago, when man first peopled the Americas (Briones et al. 1999, Macedo et al. 2001). Thus, it is natural suppose that not all T. cruzi strains can infect humans and cause Chagas disease. As pointed out above, it is increasingly evident that in Brazil the human disease is much more associated with $T$. cruzi II strains, although some $T$. cruzi I and $T$. cruzi III could be eventually involved. However, it is not clear yet what factors determine the different clinical forms of the disease. Although we cannot discard the influence of patient-associated factors, an important role of the parasite genetics is nowadays recognized (Vago et al. 1996). On the other hand, many studies have been unsuccessful in correlating specific elements of the variability of the parasites with the clinical characteristics of the disease (Morel et al. 1980, Macedo et al. 1992). One possible explanation for this is that strains of T. cruzi represent swarms of clones that may present symbiotic relationships, but also compete fiercely for available resources. In addition, because of biological polymorphism, different clones from a strain may present tropism for different tissues (cardiac muscle, myoenteric plexuses in the esophagus and rectum, etc.), and thus an important factor determining the clinical course of disease might be the specific "constellation' of infecting clones in the swarm and their specific tropisms. Since most of genetic profiling techniques used for the genetic characterization of $T$. cruzi require parasite isolation from patient blood and growth in laboratory animals or cultures, there is ample opportunity for clonal selection and consequently the trypanosome populations available for analysis can differ from those actually causing the tissue lesion. This scenario constitutes the core of what we have called the 'clonal-histotropic model' of Chagas disease (Macedo \& Pena 1998, Macedo et al. 2001). Our recent demonstration that it is possible to achieve genetic typing of $T$. cruzi directly from clinical tissues by LSSP-PCR (Vago et al. 1996a, b, 2000), rDNA (J Freitas et al. manuscript in preparation) or microsatellite analysis (J Pimenta, AM Macedo, manuscript in preparation) provides invaluable tools to study the molecular epidemiology of Chagas disease. When applied to experimentally double infected mice with JG and Col1.7G2 populations, these techniques revealed a perfect concordance between the T. cruzi DNA profile obtained from the hearts with the JG strain and from the recta and the clone $\mathrm{Col}$ $1.7 \mathrm{G} 2$ of the same animals (Andrade et al. 1999). Similarly Vago et al. (2000) clearly demonstrated that different $T$. cruzi population could be associated to the heart or esophagus of single patients. Taking together these results open new vistas for a better understanding of the pathogenesis of the Chagas disease. 


\section{REFERENCES}

Adad SJ, Andrade DCS, Lopes ER 1991. Contribuição ao estudo da anatomia patológica do megaesôfago chagásico. Rev Inst Med Trop São Paulo 33: 443-450.

Alves AM, de Almeida DF, von Kruger WM 1996. Genomic variation in Trypanosoma cruzi clonal cultures. Parasitol Res 82: 410-415.

Amato Neto V, Pasternak J, Matsubara L, Hammerschlak N, Carignani FL 1996. Trials for the use of gamma rays in the prevention of Trypanosoma cruzi transfusion infection. Rev Soc Bras Med Trop 29: 613-614.

Andrade LO, Machado CRS, Chiari E, Pena SDJ, Macedo AM 1999. Genetic variability of Trypanosoma cruzi implications for the pathogenesis of Chagas disease. Mol Bioch Parasitol 100: 163-172.

Andrade SG 1974. Caracterização de cepas de Trypanosoma cruzi isoladas no Recôncavo Baiano. Ver Patol Trop 3: 65121.

Andrade SG, Magalhães JB 1997. Biodemes and zymodemes of Trypanosoma cruzi strains: correlations with clinical data and experimental pathology. Rev Soc Bras Med Trop 30: $27-35$.

Arruda MV, Reinach FC, Colli W, Zingales B 1990. Sequence of $24 \mathrm{~S}$ ribosomal RNA gene and characterization of a corresponding pseudogene from Trypanosoma cruzi. Mol Biochem Parasitol 40: 35-42.

Augusto-Pinto L, Pimenta JR, Teixeira SMR, Fernandes O, Chiari E, Pena SDJ, Macedo AM, Machado CR 2003. Multilocus genotype data provide evidences that hybrid Trypanosoma cruzi strains constitute a third major lineage. Int $J$ Parasitol in press.

Ayala FJ 1993. Trypanosoma and Leishmania have clonal population structures of epidemiological significance. Biol Res 26: 47-63.

Barret TV, Hoff RH, Mott KE, Miles MA, Godfrey DG, Teixeira R, Almeida de Souza JA, Sherlock IA 1980. Epidemiological aspects of tree Trypanosoma cruzi: two types of parsite populations presenting distinct characteristics. $\mathrm{PAHO} \mathrm{Sci}$ entific Pub 347: 11-21.

Bogliolo AR, Lauria-Pires L, Gibson WC 1996. Polymorphisms in Trypanosoma cruzi: evidence of genetic recombination. Acta Trop 61: 31-40.

Borst P, Greaves D 1986. Discontinuous transcription and antigenic variation in trypanosomes. Annu Rev Biochem 55: 701-732.

Brandariz S, Schijman A, Vigliano C, Arteman P, Viotti R, Beldjord C, Levin MJ 1995. Detection of parasite DNA in Chagas' heart disease. Lancet 346: 1370-1371.

Brener Z 1987. Pathogenesis and immunopathology of chronic Chagas disease. Mem Inst Oswaldo Cruz 82: 205-212.

Brener Z 1992. Immune Response and Immunopathology in Trypanosoma cruzi Infection Chagas Disease (American Trypanosomiasis): its Impact on Transfusion and Clinical Medicine, ISBT Brazil'92, São Paulo, p. 31-47.

Briones MR, Souto RP, Stolf BS, Zingales 1999. The evolution of the two Trypanosoma cruzi subgroups inferred from rRNA genes can be correlated with the interchange of American mammalian faunas in the cenozoic and has implications to pathogenicity and host specificity. Mol Biochem Parasotol 104: 219-232.

Brisse S, Dujardin JC, Tibayrenc M 2000. Identification of six Trypanosoma cruzi lineages by sequence-characterised amplified region markers. Mol Biochem Parasitol 111: 95105.

Brisse S, Verhoef J, Tibayrenc M 2001. Characterisation of large and small subunit rRNA and mini-exon genes further supports the distinction of six Trypanosoma cruzi lineages. Int J Parasitol 31: 1218-26.

Buscaglia CA, Di Noia JM 2003. Trypanosoma cruzi clonal diversity and the epidemiology of Chagas disease. Microbes Infect 5: 419-427.

Carneiro M, Chiari E, Gonçalves AM, Pereira AAS, Morel C, Romanha AJ 1990. Changes in the isoenzyme and kinetoplast DNA patterns of Trypanosoma cruzi strains induced by maintenance in mice. Acta Trop 47: 35-45.

Carrasco HJ, Frame IA, Valente SA, Miles MA 1996. Genetic exchange as a possible source of genomic diversity in sylvatic populations of Trypanosoma cruzi. Am J Trop Med Hyg 54: 418-424.

Clark CG, Pung OJ 1994. Host specificity of ribosomal DNA variation in sylvatic Trypanosoma cruzi from North America. Mol Biochem Parasitol 66: 175-179.

Deane MP, Sousa MA, Pereira NP, Gonçalves AM, Momen H, Morel C 1984. Trypanosoma cruzi: inoculation schedules and re-isolation methods selected individual strains from doubly infected mice, as demonstrated by schizodeme and zymodeme analyses. J Protozool 31: 276-280.

Devera R, Fernandes O, Coura JR 2003. Should Trypanosoma cruzi be called "cruzi" complex? A review of the parasite diversity and the potential of selecting population after in vitro culturing and mice infection. Mem Inst Oswaldo Cruz, 98: $1-12$.

Dias JCP 1992. Epidemiology of Chagas disease. In S Wendel, Z Brener, M S Camargo, A Rassi (eds), Chagas Disease (American Trypanosomiasis): its Impact on Transfusion and Clinical Medicine, ISBTBrazil'92, São Paulo, p. 49-80.

Dias Neto E, Steindel M, Passos LK, de Souza CP, Rollinson D, Katz N, Romanha AJ, Pena SD, Simpson AJ 1993. The use of RAPDs for the study of the genetic diversity of Schistosoma mansoni and Trypanosoma cruzi. EXS 67: 339-345.

Dujardin JC, Dujardin JP, Tibayrenc M, Timperman G, De Doncker S, Jacquet D, Arevalo J, Llanos-Cuentas A, Guerra H, Bermudez H 1995. Karyotype plasticity in neotropical Leishmania: an index for measuring genomic distance among L. (V.) peruviana and L. (V.) braziliensis populations. Parasitology 110: 21-30.

Ebert F 1982. The identication of two main-groups of Trypanosoma cruzi stocks from Brazil by their isoenzyme patterns of isoelectrofocusing. Tropenmed Parasitol 33: 140-146.

Fernandes O, Mangia RH, Lisboa CV, Pinho AP, Morel CM, Zingales B, Campbell DA, Jansen AM 1999. The complexity of the sylvatic cycle of Trypanosoma cruzi in Rio de Janeiro state (Brazil) revealed by the non-transcribed spacer of the mini-exon gene. Parasitology 118: 161-166.

Fernandes O, Santos SS, Cupolillo E, Mendonça B, Derre R, Junqueira ACV, Santos LC, Sturm NR, Naiff RD, Barrett TB, Campbell DA, Coura JR 2001. A mini-exon multiplex polymerase chain reaction to distinguish the major groups of Trypanosoma cruzi and Trangeli in the Brazilian Amazon. Trans R Soc Trop Med Hyg 95: 97-99.

Fernandes O, Sturm NR, Derre R, Campbell DA 1998. The mini-exon gene: a genetic marker for zymodeme III of Trypanosoma cruzi. Mol Biochem Parasitol 95: 129-133.

Fujieda S, Tanaka N, Sunaga H, Noda I, Sugimoto C, Tsuzuki H, Saito H 1998. Expression of hMSH2 correlates with in vitro chemosensitivity to CDDP cytotoxicity in oral and oropharyngeal carcinoma. Cancer Lett 132: 37-44.

Gaunt MW, Yeo M, Frame IA, Stothard JR, Carrasco HJ, Taylor MC, Mena SS, Veazey P, Miles GA, Acosta N, de Arias AR, Miles MA 2003. Mechanism of genetic exchange in American trypanosomes. Nature 421: 936-939.

Gibson W, Stevens J 1999. Genetic exchange in the trypa- 
nosomatidae. Adv Parasitol 43: 1-46

Henriksson J, Dujardin JC, Barnabe C, Brisse S, Timperman G, Venegas J, Pettersson U, Tibayrenc M, Solari A 2002. Chromosomal size variation in Trypanosoma cruzi is mainly progressive and is evolutionarily informative. Parasitology 124: 277-286.

Henriksson J, Porcel B, Rydaker M, Ruiz A, Sabaj V, Galanti N, Cazzulo JJ, Frasch AC, Pettersson U 1995. Chromosome specific markers reveal conserved linkage groups in spite of extensive chromosomal size variation in Trypanosoma cruzi. Mol Biochem Parasitol 73: 63-74.

Henriksson J, Solari A, Rydaker M, Sousa OE, Pettersson U 1996. Karyotype variability in Trypanosoma rangeli. Parasitology 112: 385-391.

Hernandez R, Rios P, Valdes AM, Pinero D R 1990. Primary structure of Trypanosoma cruzi small-subunit RNA coding region: comparison with other trypanosomatids. Mol Biochem Parasitol 41: 207-212.

Higo H, Yanagi T, Matta V, Agatsuma, Cruz-Reyes A, Uyema N, Monroy C, Kanbara H, Tada I 2000. Genetic structure of Trypanosoma cruzi in american continents: special emphasis on sexual reproduction in Central America. Parasitology 121:403-408.

Higuchi ML, Gutierrez PS, Aiello VD, Palomino S, Bocchi E, Kalil J, Bellotti G, Pileggi F 1993. Correlation between Trypanosoma cruzi parasitism and myocardial inflammatory infiltrate in human chronic chagasic myocarditis: light microscopy and immunohistochemical findings. Cardiovasc Pathol 2: 101-105.

Hsieh P 2001. Molecular mechanisms of DNA mismatch repair. Mutat Res 486: 71-87.

Jones EM, Colley DJ, Tostes S, Lopes ER, Vnencak-Jones CL, McCurley TL 1993. Amplification of a Trypanosoma cruzi DNA sequence from inflammatory lesions in human chagasic cardiomyopathy. Am J Trop Med Hyg 48: 348-357.

Kalil J, Cunha-Neto E 1996. Autoimmunity in Chagas disease cardiomyopathy: fulfilling the criteria at last? Parasitol Today 12: 396-399.

Kawashita SY, Sanson GF, Fernandes O, Zingales B, Briones MR 2001. Maximum-likelihood divergence date estimates based on rRNA gene sequences suggest two scenarios of Trypanosoma cruzi intraspecific evolution. Mol Biol Evol 18: 2250-2259.

Köeberle F 1968. Chagas disease and Chagas syndromes: the pathology of American trypanosomiasis. Adv Parasitol 6: 63-116.

Lambrech FL 1965. Biological variations in trypanosomes and their relation to the epidemiology of Chagas' disease. Rev Inst Med Trop São Paulo 7: 346-352.

LeClerc JE, Li B, Payne WL, Cebula TA 1996. High mutation frequencies among Escherichia coli and Salmonella pathogens. Science 274: 1208-1211.

Leon W, Foutz DL, Manning J 1978. Sequence arrangement of $16 \mathrm{~S}$ and $26 \mathrm{~S}$ rRNA genes in the pathogenic haemoflagellate Leishmania donovani. Nucleic Acids Res 5: 491-504.

Lopes ER, Rocha A, Meneses AC, Lopes MAB, Fatureto MC, Lopes GP, Chapadeiro E 1989. Prevalência de megas em necrópsias realizadas no Triângulo Mineiro no período de 1954 a 1988. Rev Soc Bras Med Trop 22: 211-215.

Luquetti AO, Miles MA, Rassi A, de Rezende JM, de Souza AA, Povoa MM, Rodrigues I 1986. Trypanosoma cruzi: zymodemes associated with acute and chronic Chagas' disease in central Brazil. Trans R Soc Trop Med Hyg 80: 462470.

Macedo AM, Martins MS, Chiari E, Pena SDJ 1992. DNA finger-printing of Trypanosoma cruzi: a new tool for char- acterization of strains and clones. Mol Biochem Parasitol 55: $147-154$.

Macedo AM, Pena SDJ 1998. Genetic variability of Trypanosoma cruzi: implications for the pathogenesis of Chagas disease. Parasitol Today 14:119-123.

Macedo AM, Pimenta JR, Aguiar RS, Melo AI, Chiari E, Zingales B, Pena SD, Oliveira RP AM 2001. Usefulness of Microsatellite Typing in Population Genetic Studies of Trypanosoma cruzi. Mem Inst Oswaldo Cruz 96: 407-413.

Machado CA, Ayala FJ 2001. Nucleotide sequences provide evidence of genetic exchange among distantly related lineages of Trypanosoma cruzi. Proc Natl Acad Sci USA 98: 7396-7401

Machado CA, Ayala FJ 2002. Sequence variation in the dihydrofolate reductase-thymidylate synthase (DHFR-TS) and trypanothione reductase (TR) genes of Trypanosoma cruzi. Mol Biochem Parasitol 121: 33-47.

Marques-Araújo, Chiari E 1988. Caracterização biológica de clones das cepas Y, CL e MR de Trypanosoma cruzi em camun-dongos $\mathrm{C} 3 \mathrm{H}$ isogênicos. Mem Inst Oswaldo Cruz 83: 175-181.

Miles MA, Apt BW, Widmer G, Povoa MM, Schofield CJ 1984. Isoenzyme heterogeneity and numerical taxonomy of Trypanosoma cruzi stocks from Chile. Trans $R$ Soc Trop Med Hyg 78: 526-535.

Miles MA, Lanhan SM, de Souza AA, Povoa DG 1980. Further enzymic characters of Trypanosoma cruzi and their evaluation for strain identification. Trans $R$ Soc Trop Med Hyg 74: 221-242.

Miles MA, Souza AA, Povoa M, Shaw JJ, Lainson R, Toye PJ 1978. Isozymic heterogeneity of Trypanosoma cruzi in the first autochthonous patients with Chagas' disease in Amazonian Brazil. Nature 272: 819-821.

Miles MA, Toye PJ, Oswald SC, Godfrey DG et al 1977. The identification by isoenzyme patterns of two distinct strain groups of Trypanosoma cruzi, circulating independently in a rural area of Brazil. Trans R Soc Trop Med Hyg 71: 217225.

Momen H 1999. Taxonomy of Trypanosoma cruzi: a commentary on characterization and nomenclature. Mem Inst Oswaldo Cruz 94: 181-184.

Morel C, Chiari E, Camargo EP, Mattei DM, Romanha AJ, Simpson L 1980. Strains and clones of Trypanosoma cruzi can be characterized by pattern of restriction endonuclease products of kinetoplast DNA minicircles. Proc Natl Acad Sci USA 77: 6810-6814.

Muhlpfordt H, Berger J 1990. Characterization and grouping of Trypanosoma cruzi stocks by DNA base-specific fluorochromes and discriminate analysis. Parasitol Res 76: 319325.

Murthy VK, Dibbern KM, Campbell DA 1992. PCR amplification of mini-exon genes differentiates Trypanosoma cruzi from Trypanosoma rangeli. Mol Cell Probes 6: 237-243.

Nunes LR, de Carvalho MR, Buck GA 1997. Trypanosoma cruzi strains partition into two groups based on the structure and function of the spliced leader RNA and rRNA gene promoters. Mol Biochem Parasitol 86: 211-224.

Oliveira RP 1997. Estudos Genéticos e Evolucionários do Trypanosoma cruzi, PhD Thesis, Universidade Federal de Minas Gerais, Belo Horizonte.

Oliveira RP, Broude NE, Macedo AM, Cantor CR, Smith CL, Pena SDJ 1998. Probing the genetic population structure of Trypanosoma cruzi with polymorphic microsatellites. Proc Natl Acad Sci USA 95: 3776-3780.

Oliveira RP, Macedo AM, Chiari E, Pena SDJ 1997. An alternative approach to evaluating the intraspecific genetic variability of parasites. Parasitol Today 13: 196-200. 
Oliveira RP, Melo AIR, Macedo AM, Chiari E, Pena SDJ 1999. The population structure of Trypanosoma cruzi: expanded analysis of 54 strains using eight polymorphic CA-repeat microsatellites. Mem Inst Oswaldo Cruz 94: 65-70.

Palacius-Pru E, Carrasco H, Scorza C, Espinoza R 1989. Ultrastructural characteristics of different stages of human chagasic myocarditis. Am J Trop Med Hyg 41: 29-40.

Pedroso A, Cupolillo E, Zingales B 2003. Evaluation of Trypanosoma cruzi hybrid stocks based on chromosomal size variation. Mol Biochem Parasitol 129: 79-90.

Peltomaki P 2003. Role of DNA mismatch repair defects in the pathogenesis of human cancer. J Clin Oncol 21: 1174-1179.

Pena, SDJ, Simpson AJG 1996. Sequence-specific gene signatures produced by LSSP-PCR. In U Landegren, Laboratory Protocols for Mutation Detection, Oxford University Press, Oxford, p. 42-47.

Pena SD, Barreto G, Vago AR, De Marco L, Reinach FC, Dias Neto E, Simpson AJ 1994. Sequence-specific "gene signatures" can be obtained by PCR with single specific primers at low stringency. Proc Natl Acad Sci USA 91: 1946-1949.

Pimenta JR 2002. Análises Filogenéticas Populacionais em T. cruzi a Partir de Estudos de Microssatélites Polimórficos de DNA, PhD Thesis, Universidade Federal de Minas Gerais, Belo Horizonte.

Porcile PE, Santos MR, Souza RT, Verbisck NV, Brandao A, Urmenyi T, Silva R, Rondinelli E, Lorenzi H, Levin MJ, Degrave W, Franco da Silveira J 2003. A refined molecular karyotype for the reference strain of the Trypanosoma cruzi genome project (clone CL Brener) by assignment of chromosome markers. Gene 308: 53-65.

Prata A 2001. Clinical and epidemiological aspects of Chagas disease. Lancet Infec Dis 1: 92-100.

Romanha AJ, Pereira da Silva AA, Chiari E, Kilgour, V 1979. Isoenzyme patterns of cultured Trypanosoma cruzi: changes after prolonged subculture. Comp Biochem Physiol 62B: 139-142.

Santos, FR, Pandya, A, Tyler-Smith, C, Pena, SDJ, Schanfield, M, Leonard, WR, Osipova, L, Crawford, MH, Mitchell, RJ 1999. The central Siberian origin for native American chromosomes. Am J Hum Genet 64: 619-628.

Santos MR, Cano MI, Schijman A, Lorenzi H, Vazquez M, Levin MJ, Ramirez JL, Brandão A, Degrave WM, da Silveira JF 1997. The Trypanosoma cruzi genome project: nuclear karyotype and gene mapping of clone CL Brener. Mem Inst Oswaldo Cruz 92: 821-828.

Satellite Meeting 1999. Recommendations from a satellite meeting. Mem Inst Oswaldo Cruz 94: 429-432.

Schmuñis, GA 1987. Autoimmunity in Chagas' disease. Mem Inst Oswaldo Cruz 82: 287-310.

Schon I, Martens K 2003. No slave to sex. Proc R Soc Lond B Biol Sci 270: 827-833.

Schottelius J 1982. The identification by lecitins of two strain groups of Trypanosoma cruzi. Z Parasitenk 68: 147-154.

Skaletsky H, Kuroda-Kawaguchi T, Minx PJ, Cordum HS, Hillier L, Brown LG, Repping S, Pyntikova T, Ali J, Bieri T, Chinwalla A, Delehaunty A, Delehaunty K, Du H, Fewell G, Fulton L, Fulton R, Graves T, Hou SF, Latrielle P, Leonard S, Mardis E, Maupin R, McPherson J, Miner T, Nash W, Nguyen C, Ozersky P, Pepin K, Rock S, Rohlfing T, Scott K, Schultz B, Strong C, Tin-Wollam A, Yang SP, Waterston RH, Wilson RK, Rozen S, Page DC 2003. The male-specific region of the human Y chromosome is a mosaic of discrete sequence classes. Nature 423: 825-837.

Souto RP, Zingales B 1993. Sensitive detection and strain classification of Trypanosoma cruzi by amplification of a ribosomal RNA sequence. Mol Biochem Parasitol 62: 45-52.

Souto RP, Fernandes O, Macedo AM, Campbell, Zingales B
1996. DNA markers define two major phylogenetic lineages of Trypanosoma cruzi. Mol Biochem Parasitol 83: 141-152.

Steindel M, Dias Neto E, Menezes C, Romanha A, Simpson AJG 1993. Random amplified polymorphic DNA analysis of Trypanosoma cruzi strains. Mol Biochem Parasitol 60: 71-80.

Stothard J, Frame I, Miles M 1999. Genetic diversity and genetic exchange in Trypanosoma cruzi: dual drug-resistant "progeny" from episomal transformants. Mem Inst Oswaldo Cruz 94: 189-193.

Sturm NR, Vargas NS, Westenberger SJ, Zingales B, Campbell DA 2003. Evidence for multiple hybrid groups in Trypanosoma cruzi. Int J Parasitol 33: 269-279.

Tait A 1980. Evidence for diploidy and mating in trypanosomes. Nature 287: 536-538.

Takeda GK, Campos R, Kieffer J, Moreira AA, Amato Neto V, Castilho VL, Pinto PL, Duarte MI 1986. Ação de raios gama sobre formas sanguícolas de Trypanosoma cruzi. Estudo experimental em camundongos. Rev Inst Med Trop Sao Paulo 28: 15-18.

Tanowitz HB 1992. Chagas disease. Clin Microbiol 5: 400-419.

Tibayrenc M 1995. Population genetics of parasitic protozoa and other microorganisms. Adv Parasitol 36: 47-115.

Tibayrenc M 1998. Genetic epidemiology of parasitic protozoa and other infectious agents: the need for an integrated approach. Int J Parasitol 28: 85-104.

Tibayrenc M, Ayala FJ 1987. High correlation between isoenzyme classification and kinetoplast DNA variability in Trypanosoma cruzi. C R Acad Sci III 304: 89-92.

Tibayrenc M, Ayala F 1988. Isoenzyme variability of Trypanosoma cruzi, the agent of Chagas' disease: genetic, taxonomic and epidemiological significance. Evolution 42: $277-$ 292.

Tibayrenc M, Miles MA 1983. A genetic comparison of Brazilian and Bolivian zymodemes of Trypanosoma cruzi. Trans $R$ Soc Trop Med Hyg 77: 76-83.

Tibayrenc M, Echalar L, Dujardin, P Poch O, Desjeux P 1984. The microdistribution of isoenzymic strains of Trypanosoma cruzi in Southern Bolivia: new isoenzyme profiles and futher arguments against Mendelian sexuality. Trans $R$ Soc Trop Med Hyg 78: 519-525.

Tibayrenc M, Neubauer K, Barnabé C, Guerrini F, Skarecky D, Ayala F 1993. Genetic characterization of six parasitic protozoa: parity between random primer DNA typing and multilocus enzyme electrophoresis. Proc Natl Acad Sci USA 90: 1335-1339.

Tibayrenc M, Ward P, Moya A, Ayala FJ 1986. Natural populations of Trypanosoma cruzi, the agent of Chagas disease, have a complex multiclonal structure. Proc Natl Acad Sci USA 83: 115-119.

Vago AR, Andrade LO, Leite AA, d'Avila Reis D, Macedo AM, Adad SJ, Tostes S Jr, Moreira MC, Filho GB, Pena SD 2000. Genetic characterization of Trypanosoma cruzi directly from tissues of patients with chronic Chagas disease: differential distribution of genetic types into diverse organs. Am J Hum Pathol 156: 1805-1809.

Vago AR, Macedo AM, Adad SJ, Reis DA, Corrêa-Oliveira R 1996a. PCR detection of Trypanosoma cruzi DNA in esophageal tissues of patients with chronic Chagas disease. Lancet 348: 891-892.

Vago AR, Macedo AM, Oliveira RP, Andrade LO, Chiari E, Galvão LMC, Simpson AJG, Tostes S, Pena SDJ 1996b. Kinetoplast DNA signatures of Trypanosoma cruzi strains obtained directly from infected tissues. Am J Pathol 149: 2153-2159.

Vianna G 1911. Contribuição para o estudo da anatomia 
patológica da moléstia de Chagas. Mem Inst Oswaldo Cruz. 3: 276-293.

Welch DM, Meselson M 2000. Evidence for the evolution of Bdelloid rotifers without sexual reproduction or genetic exchange. Science 288: 1211-1215.

Zeledon R, Rabinovich JE 1981. Chagas' disease: an ecological appraisal with special emphasis on its insect vectors. Annu Rev Entomol 26: 101-33.

Zhang Q, Tibayrenc M, Ayala FJ 1988. Linkage disequilibrium in natural populations of Trypanosoma cruzi (Flagellate), the agent of Chagas' disease. J Parasito l 35: 81-85.

Zillman U, Ebert F 1983. The characterization of Trypanosoma cruzi stocks by starch gel electrophoresis, comparison of results with those of isoeletric focusing. Tropemmed Parasitol 34: 84-88.

Zingales B, Souto RP, Mangia RH, Lisboa CV, Campbell DA, Coura JR, Jansen A, Fernandes O 1998. Molecular epidemiology of American trypanosomiasis in Brazil based on dimorphisms of rRNA and mini-exon gene sequences. Int $J$ Parasitol 28: 105-112.

Zingales B, Stolf BS, Souto RP, Fernandes O, Briones MR 1999. Epidemiology, biochemistry and evolution of Trypanosoma cruzi lineages based on ribosomal RNA sequences. Mem Inst Oswaldo Cruz 94: 159-164. 